\title{
Catadoras de Si: o Que Você Faz Com Seu Lixo? Projeto de extensão, dança e documentário
}

\author{
Daniela Isabel Kuhn ${ }^{1}$ \\ Nanci Stancki da Luz ${ }^{2}$
}

\section{Resumo:}

O texto trata da proposta de dança desenvolvida em um projeto de extensão realizado com catadoras(es) de material reciclável. As ações envolveram oficinas de dança para os participantes, a criação e apresentação do espetáculo "Catadoras de si" e de um documentário sobre todo o processo. Os objetivos centrais foram contribuir para a construção de uma identidade mais positiva das(os) catadoras(es) e estimular a sensibilização do público que assistiu ao espetáculo e ao documentário.

Plavras-chave: Dança, Catadoras de material reciclável, Sensibilização

\begin{abstract}
:
This paper depicts the project of dance developed in an extension program involving pickers of recyclable material. The action involved dance workshops for the participants, the creation and presentation of the dance performance "Catadoras de si" and a documentary about the whole process. The main focus was to contribute to building up a more positive identity for the pickers of recyclable material, as well as to stimulate the awareness of the audience that watched the performance and the documentary.
\end{abstract}

Key-words: Dance, Pickers of Recyclable Material, Awareness.

1 Professora do curso de bacharelado em Educação Física da UTFPR; Bacharelado e Licenciatura em Dança (UNICAMP), Mestre em Artes (UNICAMP); Doutoranda do Programa de Pós-graduação em Tecnologia e Sociedade(UTFPR). E-mail: kuhndaniela@hotmail.com

2 Doutora em Política Científica e Tecnológica (UNICAMP); Professora do Programa de Pós-graduação em Tecnologia e do Departamento Acadêmico de Matemática (UTFPR).E-mail: nancist@terra.com.br 
O público aguarda no hall de entrada no Auditório da Universidade Tecnológica Federal do Paraná (UTFPR) em Curitiba, no dia 08 de abril de 2011, para apreciar o espetáculo de dança "Catadoras de si: o que você faz com seu lixo?". Quando as portas do teatro se abrem o espetáculo já está iniciando. Não há ninguém dançando no palco, mas o convite foi feito: adentramos no lixo, na ação de catar, no corpo camuflado pelo lixo. A pergunta e a poesia iniciam-se: "o que você faz com seu lixo? O que seu lixo faz com você?"

Foram três dias de apresentação. No primeiro dia tivemos um público especial: as catadoras e os catadores de material reciclável que participaram da pesquisa. Organizamos nosso trabalho para que parte da equipe de pesquisadoras(es) buscasse as(os) catadoras(es) em seu local de trabalho com o ônibus da Universidade Federal do Paraná (UFPR) e um grupo de alunos aguardava-os(as) na UTFPR ${ }^{1}$. Este grupo acolheu as(os) filhas(os) das(os) catadoras(es) e realizou uma proposta de recreação e lazer em outra sala da universidade, para que suas mães e seus pais pudessem assistir ao espetáculo com maior tranquilidade.

Ao mesmo tempo que o espetáculo era dançado pelas bailarinas-criadoras Luiza Santini e Valleska Zych, catadoras de sua própria dança, com a inspiradora e dinâmica trilha musical de Rodrigo Lemos, Lucas Amado iluminava cada cena produzindo cor, volume e textura aos movimentos e histórias das personagens Maria Rita e Maria Teresa. Também o documentário desta pesquisa continuava a ser registrado. Continuava, pois desde setembro de 2010 o diretor João Marcelo Gomes acompanhou nossos laboratórios de criação, ensaios, o desenvolvimento das oficinas com as(os) catadoras(es), a composição da trilha sonora, dos figurinos e do cenário.

Este é um breve relato de alguns momentos do projeto de extensão que realizamos: “Do Lixo à Dança: Resgate da Identidade Pessoal e Coletiva dos Catadores de Material Reciclável de Piraquara$\mathrm{PR}^{2 \prime}$. O projeto teve como principais objetivos a identificação das possíveis marcas geradas pela marginalização das(os) catadoras(es) de lixo reciclável e a intenção de contribuir para a reconstrução de uma identidade mais positiva e consequente conquista da autonomia dos participantes, atuando na qualidade de vida e contribuindo para que as(os) catadoras(es) se sintam estimulados a transformar sua realidade social. Foram produzidas duas obras artísticas - o espetáculo de dança e o documentário, ambos com o mesmo nome "Catadoras de si: o que você faz com seu lixo?" - com o intuito estimular a conscientização e sensibilização do público que as assistiu sobre a relação que cada pessoa estabelece com a realidade social destas(es) trabalhadoras(es), bem como com o lixo, num sentido mais objetivo (relacionado à reciclagem) e mais subjetivo (relacionado ao "lixo" emocional interno de cada um). Nossas ações dialogam com o potencial que a dança possui de gerar sensibilização, conscientização e transformação.

Para tanto, atuamos alicerçados pela metodologia da pesquisa-ação (THIOLLET,1997; BARBIER, 2007), articulada com a abordagem de dança "bailarino-pesquisador-intérprete" (BPI), criada pela professora Graziela Rodrigues $(1997,2003)$. Consideramos que a escolha de realizarmos este estudo a partir da temática "trabalho - qualidade de vida - identidade pessoal" tendo a dança como principal fio condutor conduziu-nos a lidar diretamente com os aspectos de nossa personalidade, corporeidade e com nossos afetos, tanto das pesquisadoras, como das(os) participantes.

1 Este projeto foi realizado em colaboração com a UFPR, sob a coordenação da Prof ${ }^{a}$ Marcia Oliveira. Na UTFPR a Prof ${ }^{a}$ Leandra Ulbricht foi atuante em nosso projeto.

2 O citado projeto contou com financiamento da Fundação Araucária de duas formas: bolsa de extensão do programa "Ações Afirmativas" para a aluna Luiza Santini e financiamento do espetáculo de dança e do documentário pelo edital de "Pesquisa Básica e Aplicada". O projeto foi aprovado no Comitê de ética da UFPR sob o registro CEP/ SD: 861.196.09.12 e CAAE: 5283.0.000.091-09 aprovado em 10 de março de 2010. 
Dessa forma, fez-se necessário uma atuação na pesquisa que possibilitasse lidar com as subjetividades, com a sensibilidade, com a oportunidade de trocas humanas como forma de construção de novas possibilidades do viver de cada pessoa envolvida no trabalho. Isto nos remete ao trabalho que René Barbier (2000) vem desenvolvendo, pois o autor aponta que a escolha metodológica da pesquisa-ação exige uma conduta como pesquisadoras(es) que implicará num envolvimento que perpassará pelas relações afetivas - nível psicoafetivo -, mobilizando aspectos de nosso própria história - nível histórico-existencial - e redimensionando características de nossa forma de realizar o trabalho de pesquisa - nível estrutural-profissional.

O projeto de extensão desenvolveu-se em uma associação de catadoras e catadores de material reciclável na cidade de Piraquara-PR, região metropolitana de Curitiba. Esta associação é formada por 08 a 12 componentes (sempre um número flutuante). Nas oficinas participaram entre 04 a 08 pessoas, pois nem sempre todos estavam presentes no local de trabalho e algumas vezes alguns presentes justificam que não poderiam participar da oficina por terem que realizar seu trabalho no barracão ${ }^{3}$.

Entre setembro de 2009 e final de 2011 desenvolvemos as seguintes ações junto a associação de catadores de material reciclável: pesquisa de campo, com o objetivo de co-habitar com a fonte (RODRIGUES, 1997; 2003); proposição de "oficinas de dança e desenvolvimento humano" para as catadoras(es); a elaboração do espetáculo de dança "Catadoras de Si" criado e dançado pelas alunas-pesquisadoras Valleska Zych e Luiza Santini a partir da vivência em campo, dirigido pela coordenadora do projeto Daniela Kuhn ; apresentação do espetáculo de dança para as(os) catadoras (es), para a comunidade acadêmica e para a sociedade em geral em abril de 2011; realização de um documentário em vídeo sobre todas as fases da pesquisa; divulgação do documentário em eventos, congressos e escolas.

Para compartilhar o trabalho realizado e desenvolver reflexões iremos descrever sucintamente as principais ações desenvolvidas: as oficinas de dança e desenvolvimento humano, a criação e apresentação do espetáculo "Catadoras de si" e o documentário.

\section{As oficinas de dança e desenvolvimento humano}

Inicialmente é importante salientar que para desenvolver as propostas junto as(aos) catadoras(es), as alunas extensionistas passaram por um processo de capacitação, para que estivessem melhor preparadas para a vivência em campo. As exigências da metodologia adotada - a pesquisaação - articulada as particularidades do método de dança BPI conduziu a coordenadora do projeto a considerar fundamental a realização desta capacitação. Concordamos com Franco (2005) quando afirma ser preciso tempo e habilidade para construir uma intimidade para atuar na pesquisa-ação. Para Barbier é muito importante nesta abordagem o pesquisador saber escutar, além da necessidade do envolvimento deste com “toda sua presença para o outro" (BARBIER, 2007, p.102).

Para oportunizar uma conduta das pesquisadoras na perspectiva proposta por estes autores, a capacitação concretizou-se em aulas de dança baseadas na abordagem da metodologia do "bailarinopesquisador-intérprete" (RODRIGUES, 1997, 2003). Neste sentido, as pesquisadoras entraram inicialmente em contato com sua estrutura física - considerando suas dimensões física, mental,

$3 \quad$ Mais adiante estaremos discutindo brevemente sobre a resistência de algumas(uns) trabalhadoras(es) participarem das oficinas. 
emocional e espiritual (RIBEIRO, 2000) -, com elas mesmas e com um pouco de "seus lixos internos". Esta metáfora com o lixo foi o ponto de partida do processo proposto, observando inicialmente a relação das pessoas em campo com este material e a poética existente nesta realidade, considerando o lixo interno de cada um e a possibilidade de reciclagem. Dessa forma, nesta etapa foi trabalhado com cada bailarina aspectos de sua auto-imagem nos seus desdobramentos mais positivos e negativos, num intuito que seus corpos não estivessem tão diferentes dos corpos que vão pesquisar (RODRIGUES, 1997).

Considerando que a capacitação teve o objetivo de sensibilizar e motivar o contato de cada uma com sua auto-imagem e identidade, direcionamos as bailarinas para refletirem sobre seu papel na pesquisa. Entendemos que estas aulas de dança contribuíram para uma abertura para a temática da pesquisa. Quando a(o) artista-pesquisadora(r) percebe-se como detentor de uma história, registrada em seu corpo e que, neste sentido, a pessoa é uma consequência de sua trajetória de vida, torna-se mais aberto a ver este aspecto no outro. Neste sentido, pudemos nos alinhar à abordagem de pesquisa-ação de Barbier (2002), oportunizando que se abra mão de trabalhar "sobre" o outro, mas sim "com" o outro.

Uma intenção importante das aulas de dança foi capacitar Valleska e Luiza a não colocar em primeiro plano o mecanismo de julgamento em relação ao outro, mas possibilitar a aproximação das pessoas que participam da pesquisa de campo na perspectiva da empatia. Ou seja, buscando nas relações humanas em campo os aspectos que nos aproximam como seres humanos, sem deixar de reconhecer as diferenças.

Fechada esta etapa da capacitação, iniciamos o "co-habitar" com a fonte (RODRIGUES, 1997), fazendo visitas ao barracão da associação uma vez por semana.

Em seguida, iniciamos as "oficinas de dança e desenvolvimento humano". O objetivo desta ação era estimular a consciência nas catadoras e nos catadores de sua importância como seres humanos e como trabalhadoras(es), procurando contribuir para melhorar suas relações interpessoais e auto-estima.

Antes de realizarmos as oficinas sempre propomos um trabalho de sensibilização do grupo para participarem, conversando, percebendo suas demandas e explicando os objetivos do projeto.

Nas oficinas foram propostas dinâmicas, brincadeiras, jogos e danças, balizadas de maneira clara e explícita pelos nossos objetivos. As atividades foram seguidas de reflexões críticas (ou feed back) com o intuito de colaborar para que cada participante tivesse uma percepção mais clara de sua vivência, da troca de experiência, além de estimular que o grupo vislumbrasse possibilidades de melhoria dos aspectos de sua realidade que tenham vindo à tona percebidos por elas(es) como negativos.

Dessa maneira, a proposta oportunizou tempo e espaço para a expressão da realidade interna e externa de cada pessoa, potencializando a expressividade humana. Como consequência, percebemos um exercício da capacidade de reflexão, à medida que o trabalho colaborava para uma percepção mais aguçada destas realidades.

Neste sentido, atuamos tributários à concepção de que a expressão corporal reflete tudo que somos, nossa história, o que pensamos e sentimos, pois, como coloca Klauss Vianna (2005, p. 149), "vida interior e expressão corporal são coisas inseparáveis". Como as atividades tinham como principal fio condutor a expressão pelo corpo, pudemos observar emergir conteúdos subjetivos que estavam internalizados nas pessoas. 
Para discutir algumas das conclusões sobre o projeto relataremos um exemplo de atividade. Em outubro de 2010 as (os) participantes colocaram como uma demanda a ser trabalhada nas oficinas as relações interpessoais, por julgarem, em suas palavras, que "a coisa está difícil" ${ }^{4}$. Alegaram que estava ocorrendo muitas brigas e dificuldades de diálogos construtivos. Neste sentido preparamos as oficinas para discutir e trabalhar esta demanda. Uma das propostas foi a seguinte:

- "Guiar a (o) colega com os olhos vendados": uma pessoa ficava de olhos vendados e era guiada pelo espaço por outra pessoa (esta sem venda nos olhos). Aos poucos propomos as (aos) participantes ampliar a complexidade da atividade: guiar o colega apenas com o toque de um dedo e retirar a mão, ou trocar de par sem que, a princípio, a pessoa guiada perceba, por exemplo.

Esta atividade tinha o como principal objetivo fazer cada participante perceber e refletir sobre o grau de confiança que tinham em cada uma ${ }^{5}$, como expressavam cuidado umas pelas outras e a dependência e a responsabilidade que tem uma pela outra. Após a atividade, ao realizar o feed back, as catadoras puderam reconhecer estes aspectos e refletir de maneira crítica sobre suas dificuldades nos relacionamentos no grupo e as possibilidades de melhorar estas condições, trazendo depoimentos consistentes ${ }^{6}$.

Se nos colocarmos no lugar de uma participante, podemos apreender que ao conduzir a outra pessoa nesta atividade sou motivada a perceber de maneira concreta, na concretude de minhas ações corporais - no sentido proposto por Nuno Cobra Ribeiro (2000) - minha responsabilidade, como minhas ações repercutem na vida da outra pessoa. Ao ser conduzida e confiar na outra pessoa percebo que corro riscos, mas que ainda existe cuidado e respeito nas relações. Percebo, ainda, o toque diferente que cada uma tem e como cada colega expressa cuidado, assim como as maneiras diferentes de expressar afeto.

Nos relatos das participantes foi assinalada a necessidade de confiança, sendo que este aspecto foi relacionado ao cotidiano na associação. Especificamente foi relatada pela maioria dos participantes que a "dificuldade de diálogo" acaba gerando "fofocas" que prejudicam a confiança uma na outra.

Esta conclusão relatada pelo grupo nesta atividade ocorreu em diversos momentos de nosso trabalho, o que nos reporta a Mailhiot, ao afirmar que "as relações interpessoais não podem tornar-se mais positivas, mais socializadas e o grupo integrar-se de modo definitivo enquanto subsistirem entre os membros fontes de bloqueios e de filtragens de comunicação" (MAILHIOT, 1981, p.70). Para o autor esses bloqueios ancoram-se justamente na dificuldade de diálogo, na falta de espaço e de tempo para que cada pessoa expresse com certa clareza suas necessidades e inquietações, buscando uma integração mais positiva nas relações interpessoais.

Neste sentido, visualizamos que as "oficinas de dança e desenvolvimento humano" colaboraram para que as catadoras e os catadores, ao participarem de atividades práticas e com enfoque na movimentação do corpo, tomassem consciência de seus problemas, expressassem ao grupo suas percepções e propusessem possíveis soluções.

Salientamos que a própria ação de expressar estas percepções no momento da oficina já acaba significando uma possibilidade de melhora na qualidade de comunicação do grupo, porque

4 Durante a pesquisa, fomos conquistando, aos poucos, uma relação de proximidade e uma certa confiança das (os) participantes até chegarmos ao momento descrito, no qual estas pessoas sentiram a liberdade e a confiança em expressar uma demanda que acreditavam que nossas propostas poderiam contemplar e auxiliar.

$5 \quad$ Neste dia apenas mulheres participaram.

6 A riqueza de alguns destes momentos podem ser percebidos no documentário "Catadoras de si: o que você faz com seu lixo". 
exercitou o diálogo mais franco e assertivo. $\mathrm{O}$ aspecto lúdico trabalhado na proposta e a confiança que conquistamos ao longo de meses de convivência com o grupo, possibilitaram um ambiente que contribuiu para gerar formas de comunicações um pouco mais abertas e autênticas, o que, segundo Mailhiot (1981), é fator indispensável para, que as necessidades interpessoais possam encontrar satisfações adequadas.

Não temos a ingenuidade de afirmar que as relações se transformaram plenamente, mas observamos, por outro lado, que foi possível às (aos) participantes vislumbrarem uma possibilidade de melhora. Encarando a proposta das oficinas como um processo educativo, partilhamos e sonhamos com o ideal de Paulo Freire, cônscio de que "se a educação não pode tudo, alguma coisa fundamental a educação pode" (FREIRE, 1992, p. 112).

\section{O espetáculo "Catadoras de si: o que você faz com seu lixo?"}

Todo o processo de criação do espetáculo ocorreu entre setembro de 2009 e abril de 2011, totalizando um ano e meio de trabalho. Desta forma, podemos relatar que houve muitos aspectos e desdobramentos que envolveram esta ação, que merece um texto amplo e específico a ser desenvolvido em outra oportunidade ${ }^{7}$. Portanto, aqui são apresentadas algumas questões mais relativas à conscientização e à reflexão das pessoas envolvidas no projeto e do público que assistiu ao espetáculo.

Como relatado anteriormente, a criação do espetáculo baseou-se na abordagem metodológica desenvolvida por Graziela Rodrigues $(1997,2003)$, "bailarino-pesquisador-intérprete". Trata-se de uma metodologia que tem seu conhecimento desenvolvido e sistematizado em uma prática de dança com parâmetros específicos do BPI, que, por questões de enfoque deste texto, não nos deteremos a especificar e aprofundar ${ }^{8}$.

Tomemos, porém, algumas características que nos auxiliarão na presente reflexão. Trata-se de uma metodologia de dança, que tem sua construção, fundamentação e desenvolvimento alicerçado na prática, ou seja no cotidiano da pesquisa de campo e da pesquisa no corpo da(o) bailarina(o). Neste sentido, consideramos importante relatar que a diretora do espetáculo, Daniela Kuhn, durante sua graduação em Dança na Universidade Estadual de Campinas vivenciou um processo de criação em dança na perspectiva desta metodologia, sendo orientada por Graziela Rodrigues. Ou seja, houve um processo de formação da diretora do espetáculo fundamentada na vivência prática nesta metodologia.

Além disso, devemos pontuar que no BPI as principais referências para a criação são a vivência em campo (em nosso caso com as(os) catadoras(es) de material reciclável) e a memória corporal da (o) bailarina (o). Portanto, o co-habitar com a fonte foi o mote gerador do roteiro do espetáculo.

Depois de três meses de co-habitar com a fonte, iniciamos os laboratórios de criação, dando

$7 \quad$ Produzimos um artigo que trata de alguns aspectos do processo de criação do espetáculo, sobretudo sobre o potencial de auto-conhecimento gerado pelo processo de criação da personagem Maria Teresa, dançada por Valleska Zych. Para maiores detalhamentos ver nosso artigo "Catadoras de si: o corpo como canal de conhecimento" em: http:// www.centroreichiano.com.br/artigos/Anais\%202012/KUHN,\%20Daniela\%20Isabel;\%20ZYCH,\%20Valleska. $\% 20$ Catadoras\%20de.pdf

8 Consideramos que não é o enfoque de nosso texto especificar e aprofundar tais características, devido a sua complexidade. Para aprofundamento sugerimos a leitura das obras e artigos publicados pela autora. Contudo, enfatizamos aqui que uma plena compreensão das características de qualquer processo de criação em arte somente ocorre através da vivência deste processo. 
continuidade concomitantemente à vivência em campo. Nesta etapa, tendo o objetivo de construir a personagem em cada bailarina, guiadas pela diretora, Luiza e Valleska iniciaram um percurso de imersão nas paisagens, imagens, sensações e lembranças resultantes da convivência com as mulheres e homens da associação. Partindo do pressuposto que a "personagem emerge do co-habitar com a fonte e do que essa vivência despertou na própria pessoa" (RODRIGUES, 2003, p. 121), foram propostas pela diretora dinâmicas relacionadas aos conteúdos oriundos da fonte de pesquisa.

O ponto de partida foi o lixo, a relação das pessoas com este material e o potencial poético que emerge desta realidade. Como a maioria das pessoas da associação eram mulheres, nossa relação com elas foi a mais recorrente e expressiva. Durante a pesquisa de campo foi significativo a forma como elas se mesclavam ao lixo. Como elas ficavam camufladas, com cor e cheiro de lixo.

Neste percurso, tomando como material os conteúdos que emergiram nas conversas entre a diretora e as bailarinas, nos diários de campo e nas primeiras experiências nos laboratórios, estabelecemos um mote central do processo de criação, que denominamos "corpo lixo". Estas escolhas ocorreram considerando que no método BPI durante os laboratórios a (o) bailarina (o) sempre é a referência mais importante, o que ela (e) vem a expressar corporalmente diante das propostas é o fio condutor dos caminhos a serem percorridos no processo de criação.

Para a sala de dança trouxemos o principal material de nosso trabalho: lixo. Foi proposto como exercício de criação, por exemplo, a sensação do lixo no corpo, colocando em movimento as emoções despertadas. Após alguns meses de trabalho moldamos uma questão norteadora: "o que você faz com seu lixo?". Esta problematização conduziu a uma metáfora que nos acompanhou até o final do processo, durante as apresentações, além de estar presente no documentário: um jogo poético, metafórico e simbólico que questiona sobre o que fazemos com o lixo material produzido por cada um de nós no cotidiano e o "lixo emocional interno" que resguardamos em nossa memória corporal e que temos dificuldade em assumir, lidar e reciclar.

Algumas questões que nos norteavam sobre o lixo emocional interno podem ser relatadas da seguinte maneira: existe lixo "orgânico", que apodrece e vira adubo? Existe lixo que seguramos em nossas mãos e não abrimos mão, impossibilitando espaço para o novo, o frescor, o perfume? Existe lixo que precisa ser assumido, reciclado, transformado? O que meu lixo faz comigo?

Aprofundando o percurso criativo o processo foi revelando conteúdos e delineando personagens - Maria Teresa e Maria Rita - que geraram a matéria prima para a estruturação do roteiro do espetáculo.

As personagens trouxeram-nos a permissividade para mergulharmos de maneira ainda mais sensível com o "corpo lixo" na questão "o que você faz com seu lixo?". As histórias de vida de Maria Rita e Maria Teresa - dançadas respectivamente por Luiza e Valleska - mobilizaram de maneira profunda o campo emocional de cada uma de nós e conduziram-nos a adentrar em reflexões sobre as metáforas dos lixos externo e interno.

Para conclusão do roteiro uma equipe de artistas juntou-se a nós e cada um trouxe sua rica colaboração construindo a identidade do trabalho.

\section{O espetáculo e a sensibilização}

Esta ação da pesquisa tinha como objetivo principal sensibilizar e gerar reflexões sobre como 
cada uma (um) vivencia sua relação com estas pessoas que não fazem parte da cultura "dominante", ou, estão à margem do que o senso comum julga como "normal". Também aqui, semelhante a nossa conduta na pesquisa de campo, pretendia-se oportunizar algum grau de identificação da pessoa sentada na plateia com o ser humano catadora ou catador. Ou seja, gerar a possibilidade de cada uma (um) tomar consciência de seus preconceitos e vislumbrar esta(e) trabalhadora(r) antes de tudo como um ser humano.

Neste sentido, o roteiro do espetáculo foi direcionado para assumir um objetivo de levar o espectador a atentar que essas(es) trabalhadoras(es) possuem uma história pessoal que as levaram a esta condição, procurando não assumir uma conduta valorativa em relação as condições deste trabalho. Ou seja, não era enfoque do espetáculo discutir as condições de trabalho (que concordamos ser realmente questionáveis), e ainda menos, gerar um sentimento de "pena" em relação a estas pessoas. Pretendíamos provocar outras formas de perceber estas pessoas, além daquelas legitimadas, como por exemplo: aversão, pena ou indiferença.

Para adentrarmos um pouco no argumento da obra, vale aqui citar um trecho do programa do espetáculo, de autoria da diretora:

Maria Rita e Maria Teresa convidam-nos a mergulhar no papel, no plástico, na casa de papelão, na casa de metal, na rua, no lixo. O que está fora está dentro. O que está dentro não cabe mais no corpo. Tira, coloca, arruma, guarda, escolhe, recicla. O limite de cada um está no traço fino que delineia a dignidade de ser o que se é, de ser gente, de ocupar espaço no mundo. Espaço batalhado, espaço merecido. Maria Teresa e Maria Rita perguntam a nós: O que você faz com seu lixo? (KUHN, 2011, p. 01)

O espetáculo procurou ressaltar que apesar das diferenças e das dificuldades que cada pessoa tem em sua vida, temos, como seres humanos, muito em comum. Perceber os aspectos humanos que nos igualam pode significar apontar que existe uma teia de relações sociais que nos conecta uns com os outros. Aqui podemos retomar os resultados das oficinas. Se no grupo da associação das (os) catadoras (es) foi possível perceber a necessidade de melhora nas relações e na comunicação entre as pessoas, também o espetáculo propôs discutir a necessidade que temos de trocas pessoais uns com os outros, num âmbito maior sociedade, que é construída nas relações interpessoais. Lembra que necessitamos rever o olhar que temos sobre as outras pessoas e abrir espaço para relações menos preconceituosas e mais igualitárias.

Nas oficinas pretendíamos gerar a conquista de uma melhor auto-estima e autonomia das (os) catadoras (es), promovendo condições para que os mesmos tenham uma visão mais clara de seu papel em relação ao ciclo de reciclagem, sendo hoje indispensáveis sujeitos nas questões ambientais da sociedade contemporânea. Com o espetáculo propusemos para o público uma sensibilização também neste sentido, respeitando e valorizando o papel da (o) catadora(r) de material reciclável.

\section{O documentário}

A necessidade de ampliar nossas ações e ao mesmo tempo de ter um material que registrasse e divulgasse a pesquisa estimulou-nos a realizar um documentário. Nesta ação escolhemos como objetivo principal colaborar com uma visão mais positiva da sociedade em relação às (aos) catadoras (es), procurando estimular a erradicação dos preconceitos através do viés artístico, gerando 
valorização do ser humano e do seu o trabalho.

O diretor do vídeo, João Gomes, realizou a maioria dos registros das imagens. Isto possibilitou uma percepção mais clara dos conteúdos da pesquisa e gerou uma sensível leitura dos rumos de nosso trabalho. O documentário abordou como tema central os conflitos humanos que permearam e atravessaram as várias camadas da pesquisa: as relações humanas entre as(os) catadoras(es), entre pesquisadoras e catadoras(es), entre as artistas, entre as personagens e as bailarinas.

Não cabe aqui relatar o roteiro do documentário, mas consideramos relevante discutir alguns de seus aspectos para concluir este texto .

Em junho de 2011 realizamos no auditório da UTFPR o pré-lançamento desse documentário. A intenção era finalizar esta fase da pesquisa e trazer novamente as(os) catadoras(es) participantes para a universidade com o objetivo de conhecerem o resultado do trabalho. Naquela noite apresentamos o documentário, seguido do espetáculo dançado no palco pelas duas bailarinas e um debate no final. Durante o debate o público pode realizar questionamentos que se voltaram principalmente sobre a relação entre as pesquisadoras e as(os) catadoras(es), a percepção das(os) catadoras(es) sobre o espetáculo e perguntas sobre como foi realizado o processo de criação em dança de "Catadoras de si".

Apesar desta atividade ter sido bastante proveitosa, nem todos as catadoras e os catadores puderem estar presentes, por motivos diversos. Devido a isto, decidimos então levar o documentário para dentro do barracão de reciclagem, e, assim, gerar oportunidade para que todas (os) o assistissem e realizassem seus comentários, expressassem sua opinião. No início de julho do mesmo ano projetamos o documentário na parede do barracão de reciclagem da associação. Em seguida, aplicamos um questionário que pretendia saber, na opinião de cada participante, qual o aspecto tinha sido mais relevante do documentário e realizamos uma roda de conversa para discutir as opiniões expressadas no questionário.

O diretor do documentário estava presente neste dia registrando com sua câmera todas essas ações. Os resultados desta ação foram bastante relevantes para nossa pesquisa. De maneira geral, podemos dizer que o documentário levou as(os) catadoras(es) a perceberem e refletirem sobre as resistências que apresentaram em relação as nossas propostas trabalho, o que ocasionou diversas vezes a ausência de algumas(ns) nas atividades, justificados no momento por motivos diversos.

As(os) catadoras(es) revelaram, ainda, que perceberam, através do documentário, que nós pesquisadoras também temos problemas, possibilitando a "empatia", como se o documentário oferecesse mais "transparência" nas relações, no sentido trabalhado por Mailhiot (1981). Dessa forma, as catadoras e os catadores puderam se colocar um pouco no nosso lugar, sentindo o que sentimos. Esta empatia pode gerar algo semelhante as ideias do autor:

A empatia ao outro, isto é, a capacidade de se colocar em seu lugar, facilita e favorece a objetivação do outro, ou seja, a capacidade para alguém objetivar-se com respeito às imagens ao que outro tem dele mesmo e através das quais é percebido pelos outros (MAILHOIT, 1982, p. 112).

Esta empatia vivenciada é ponto fundamental para a construção das relações em campo pois, ao adotarmos a pesquisa-ação como método, estamos assumindo que trabalharemos na perspectiva 9 Disponibilizamos de cópias do documentário para serem encaminhadas a instituições de ensino e grupos artísticos, sendo necessário as (os) interessadas (os) entrarem em contato com a coordenadora do projeto através do e-mail: kuhndaniela@hotmail.com. 
de Barbier (2002) já apontada neste texto, ou seja estaremos trabalhando "com" o outro e não "sobre" o outro, estamos de alguma forma envolvidos na vida do outro. Para trabalhar com o outro, necessito da sua confiança. A conquista da empatia mostrou-se um caminho fértil para desenvolvermos esta confiança.

Vislumbramos que as oficinas trouxeram como principal temática as relações interpessoais e a necessidade de confiança e de um espaço e tempo para um diálogo com qualidade. $\mathrm{O}$ espetáculo estabeleceu oportunidade para que fosse percebida a dimensão humana dessas (es) trabalhadoras(es), expondo e poetizando sobre suas histórias de vida - através das personagens - e procurando colaborar para uma sensibilização do público em relação à importância de respeitar as(os) catadoras(es), vislumbrando-as(os) como uma(m) fundamental ator no ciclo de reciclagem e, portanto, na preservação do meio ambiente. O documentário teve como uma conquista importante de enfatizar aspectos de uma realidade, até então não percebida sob esta perspectiva pelas(os) catadoras(es), na qual pudemos enxergar a todos como humanos, com suas limitações e possibilidade de falhas, de acertos, com seus sonhos e suas frustrações.

No mesmo sentido, as oficinas contribuíram para humanizar as(os) catadoras(es) perante elas(es) mesmas(os). O espetáculo contribui para humanizar as(os) catadoras(es) frente à comunidade. Mas, de fato, como pesquisadoras, surpreendemo-nos ao ver que o documentário nos humanizou perante as(aos) catadoras(es).

\section{Considerações Finais}

Muitos foram os momentos durante o desenvolvimento do projeto que nos encontramos questionando sobre a validade das ações, devido aos vários desafios que se impuseram nesta trajetória.

Este estudo é de difícil mensuração, na medida que objetiva transformação nas pessoas pesquisadoras, catadoras, catadores, público do espetáculo, público do documentário -, propondo colaborar para que tenham autonomia para agirem de maneira crítica, consciente e positiva.

A mobilização social para lutar por melhores condições sociais e, no caso da associação pesquisada, por melhores condições de trabalho, pode e deve partir de diferentes esferas sociais. Daqueles que aparentemente necessitam mais, devido à urgência, pois, como os catadores e as catadoras, dependem, por exemplo, da separação correta do material reciclável para sua sobrevivência. Mas, sem dúvida, também dos demais setores. Consideramos a Universidade, especialmente a pública, um local privilegiado para estas ações posto nela estão as pessoas supostamente preparadas - as(os) professoras(es) e pesquisadoras(es) - e o conhecimento para desenvolver projetos que venham a proporcionar maior interação entre o universo acadêmico e a sociedade, democratizando saberes científicos, culturais e artísticos. Trata-se de uma consistente resposta que podemos retribuir ao investimento que sociedade realiza nas instituições públicas de ensino.

No caso específico das questões ambientais - que se relacionam diretamente com o trabalho realizado pelas (os) catadoras (es) - entendemos que a construção de uma cidadania ambiental passa pela "experiência concreta dos movimentos sociais e se expressa na luta por direitos, por dimensões da democracia [...] e de transformação social" (RAMOS, 2010, p. 108). Mas propomos aqui que estas questões de dimensão macro não podem ocultar o ator mais importante desta engrenagem social: 
cada ser humano. Assim, pensamos que a construção de uma sociedade na qual cada pessoa possa ter direito a labutar por uma vida digna, passa também por ações pontuais que tenham como forte característica o aspiração por transformação através de um processo educativo, o que no projeto aqui enfocado significa, sobretudo, a educação libertadora da sensibilidade que a arte possibilita.

Esta educação tem sido construída, em nosso caso, a cada dia, em cada pequena ação, considerando cada ser humano, tanto as pesquisadoras, como as (os) catadoras (es) e o público envolvidas(os) em nosso projeto, como uma pessoa potencialmente dona de sua história. Um sujeito único, fundamental e indispensável na engrenagem social, no sonho e na realidade de construção de uma sociedade que se mobilize para uma atitude mais consciente e responsável em relação a si mesmo, as outras pessoas e ao meio ambiente.

O trabalho desenvolvido por esses homens e essas mulheres que lidam com o lixo tem uma função prática e urgente relacionados ao sustento de suas próprias vidas e de seus familiares. Mas devemos, como representantes das universidades públicas, artistas e como cidadãs(ãos), buscar compreender a importância de sua ação social, ao realizar a separação do material reciclável, possibilitando uma destinação mais ecologicamente correta do que poderia ter sido se descartado no meio ambiente. Evidenciamos, por outro lado, que se faz necessário um olhar reflexivo e crítico sobre esta realidade, posto que percebemos nesta cadeia produtiva a existência de complexidades e sutilezas nas relações econômicas e sociais. São camadas a serem pesquisadas e que poderão contribuir com um melhor entendimento da forma que nossa sociedade organiza-se e reitera ou transforma seus valores, crenças e práticas. É neste sentido que daremos continuidade a nossas pesquisas $^{10}$.

O desenvolvimento deste projeto reafirmou que as possibilidades que a dança veicula estão direcionadas para a sensibilização - seja em seu aspecto mais didático vivenciado em nosso projeto nas oficinas, seja em sua característica mais artística, concretizada no espetáculo “Catadoras de si". Sensibilizar aqui significou lembrar de as características humanas, procurando instigar em cada pessoa a possibilidade de assumir e rever nossos preconceitos, sobretudo com as pessoas que não fazem parte do que o senso comum tem considerado como a referência de normal. Aquilo que se nomeia genericamente "marginal", menor ou minoria, seja o pobre, a mulher, o negro, a cultura popular, que tem sido alocado, muitas vezes, como "o lixo da sociedade".

A possibilidade de reciclagem aqui se amplia para o potencial que a arte resguarda de estimular a transformação dos preconceitos e crenças, que pautam as escolhas. "Catadoras de si" dança pergunta: “o que seu lixo faz com você? O que você faz com seu lixo?" São propostas algumas respostas, seguindo as pistas da sensibilização que a arte pode gerar como um caminho para que cada pessoa possa ser uma catadora de si mesma.

10 Atualmente Daniela Kuhn desenvolve um projeto de pesquisa em sua pesquisa de doutorado no PPGTE, no qual estas questões citadas serão enfocadas. 


\section{Referências}

BARBIER, René. A Pesquisa-Ação. Brasília: Liber Livro, 2007.

BARBIER, René. Correio Braziliense. Brasília, 14 de julho de 2002. Entrevista concedida a Nahima Maciel. Disponível em: http://www.barbierrd.nom.fr/journal/article.php3?id_article=568. Acesso em: 20 jan. 2010.

KUHN, Daniela. Catadoras de si: o que você faz com seu lixo? Curitiba: UTFPR, Programa do espetáculo, 2011.

FERNANDES, Solange. Catadores de Papel: caminhos e descaminhos. In: Revista Agora: Políticas Públicas e Serviço Social. Ano 1, n¹, outubro 2004.

FRANCO, Maria Amélia Santoro. Pedagogia da Pesquisa-Ação. In: Educação e Pesquisa, v. 31, n. 3, p. 483-502, set./dez. São Paulo, 2005.

FREIRE, Paulo. Pedagogia da autonomia. São Paulo: Paz e Terra, 1996.

MAILHIOT, Gerald Bernard. Dinâmica e gênese dos grupos: atualidades das descobertas de Kurt Lewin. São Paulo: Duas Cidades, 1981.

MARQUES, Isabel, Ensino da Dança Hoje: Textos e Contextos, São Paulo: Cortez, 1999.

RAMOS, Elizabeth Christmann. Educação, alteridade e a construção da cidadania ambiental, In: GUÉRIOS, Ettiène; STOLTZ, Tania. Educação e Alteridade. São Carlos: Edufscar, 2010.

RIBEIRO, Nuno Cobra. A semente da vitória. São Paulo: Senac, 2000.

RODRIGUES, Graziela Estela Fonseca. Bailarino-pesquisador-intérprete: processo de formação. Rio de Janeiro: Funarte, 1997.

RODRIGUES, Graziela Estela Fonseca. O método BPI (bailarino-pesquisador-intérprete) e o desenvolvimento da imagem corporal: reflexões que consideram o discurso de bailarinas que vivenciaram um processo criativo baseado neste método. Tese (doutorado) - Instituto de Artes, Universidade Estadual de Campinas, Campinas, SP, 2003.

THIOLLENT, Michel. Pesquisa-Ação nas Organizações. São Paulo: Atlas, 1997.

VIANNA, Klauss. A Dança. São Paulo: Summus, 2005. 